\title{
Reflexões sobre o imaginário na arte literária de José Saramago: uma leitura interdisciplinar de A jangada de pedra
}

\author{
Reflections on the Imaginary in José Saramago's \\ Literature: An Interdisciplinary Approach of \\ A Jangada de Pedra
}

\author{
Maria Auxiliadora Fontana Baseio ${ }^{1}$ \\ Maria Zilda da Cunha ${ }^{2}$
}

DOI: $10.19177 /$ memorare.v8e22021221-232

\begin{abstract}
Resumo: Se, de acordo com Gilbert Durand (1997, p. 14), o imaginário pode ser compreendido como um "conjunto das imagens e relações de imagens que constitui o capital pensado do homo sapiens", o estudo dessa complexa rede semântica permite capturar o que se delineia nos pensamentos e sentimentos humanos em qualquer tempo e lugar. É objetivo deste trabalho perscrutar a constelação de imagens que se manifesta na arte literária de José Saramago. 0 corpus que serve de análise será e $A$ jangada de pedra. Pretendemos investigar a matéria imaginária que organiza esta reconhecida obra a partir dos Estudos do Imaginário na perspectiva interdisciplinar da hermenêutica simbólica, sinalizando configurações de imagens e suas relações com o contexto sócio-histórico e cultural em que se engendram. Distintas marcas históricas singularizam as formas artísticas, as várias releituras e reinvenções de imagens na formulação de apreensões estéticas. Os espaços textuais, ao se retecerem em fluxos operativos, convocam a participação do leitor para compor o diagrama de significações sugerido pelo autor. As reflexões sobre o imaginário assumem abrangência interdisciplinar, possibilitando analisar fenômenos culturais e artísticos de maneira transversal.

Palavras-chave: Imaginário. José Saramago. Interdisciplinaridade.
\end{abstract}

\begin{abstract}
If, according to Gilbert Durand (1997, p. 14), the imaginary can be understood as a "set of images and image relations that constitute the thought capital of homo sapiens", the study of this complex semantic network allows us to capture what it delineates itself in human thoughts and feelings at any time and place. The objective of this work is to examine the constellation of images that manifests itself in José Saramago's literary art. The corpus that serves as analysis will be A jangada de pedra. We intend to investigate the imaginary matter that organizes this renowned work from the point of view of the Studies of the Imaginary in the interdisciplinary perspective of symbolic hermeneutics, signaling image configurations and their relations with the socio-historical and cultural context in which they are engendered. Different historical marks single out the artistic forms, the various reinterpretations and reinventions of images in the formulation of aesthetic apprehensions. The text calls for the reader's participation to compose the diagram of meanings suggested by the author. Reflections on the imaginary take on an interdisciplinary scope, making it possible to analyze cultural and artistic phenomena in a transversal way.

Keywords: Imaginary. Saramago. Interdisciplinarity.
\end{abstract}

\footnotetext{
1 Pós-doutora em Estudos Portugueses e Lusófonos. Doutora em Letras, na área de Estudos Comparados de Literaturas de Língua Portuguesa, pela USP. Mestra em Letras pela USP. Bacharela em Letras pelo Centro Universitário Ibero-Americano (Unibero) e em Ciências Sociais pela USP. mbaseio@uol.com.br

2 Pós-doutora em Estudos Portugueses e Lusófonos. Doutora em Letras, Estudos Comparados de Literaturas de Língua Portuguesa pela USP. Mestra em Comunicação e Semiótica pela Pontifícia Universidade Católica de São Paulo (PUC-SP). Graduada em Pedagogia, em Letras e em Psicologia. mariazildacunha@hotmail.com
} 


\section{Introdução}

Neste contexto de crise material e espiritual da humanidade, em que as complexidades nos desafiam a encontrar formas inovadoras de compreensão do ser humano e de suas relações em sociedade, o imaginário emerge com força antropológica. É válido lembrar que, em várias de suas obras, sobretudo em $O$ paradigma Perdido, Edgar Morin (1999) nos mostra que a hominização se fez pela adaptação inteligente ao real (sapiens) e pela necessidade de fabulação pelo imaginário (demens).

Se, de acordo com Gilbert Durand (1997, p. 14), o imaginário pode ser entendido como uma tessitura simbólica-arquetípica, um "conjunto das imagens e relações de imagens que constitui o capital pensado do homo sapiens", o estudo dessa complexa rede de sentidos permite, de alguma forma, apreender o que se desenha em nossas subjetividades, como sentimentos e pensamentos neste nosso tempo.

São visíveis os desgastes do cartesianismo e do positivismo que caracterizavam o século XX, impregnado de marcas do mito prometeico. A mudança substancial de visão de mundo problematiza e provoca fissuras em verdades, valores e modelos explicativos que serviram de base para nosso pensar, sentir e agir por muitos séculos. 0 caráter de redes, rizomas, espectros dessas novas bases emergem evidenciando metamorfoses da racionalização clássica para uma razão sensível, no dizer de Maffesoli.

As reflexões sobre o imaginário assumem abrangência interdisciplinar nesse novo contexto, abrindo fissuras para a captura de fenômenos culturais de maneira multirreferencial. A linguagem, o mito, a arte, a religião são manifestações simbólicas que tecem a experiência humana, dada a natureza do homo symbolicum, no dizer de Cassirer (1994).

Considerando as múltiplas possibilidades de aplicação dos estudos do imaginário, neste artigo pretendemos analisar sua figuração na arte literária, em particular a do escritor José Saramago. Buscamos perscrutar a rede de imagens que tece o corpo vivo de significação, que é a obra A jangada de pedra, analisando elementos que servem de vetores à imaginação simbólica, tornando-se, assim, possível ler novos sentidos neste contexto pós-moderno. Nossa investigação se volta para a matéria imaginária que organiza este projeto estético e político do escritor português, sinalizando novas configurações do tema da viagem com imagens que traduzem o contexto pós-colonial. Observaremos como a viagem - imagem arquetípica por natureza - se tece na sintaxe de uma nova narrativa.

Cumpre esclarecer que nossa pretensão é analisar a forma como se estrutura a imaginação criadora, capaz de oferecer vias de acessibilidade ao mundo das afetividades, as quais se engendram aos processos de racionalidade, aspecto a ser sinalizado do homo sapiens demens (MORIN, 2003) neste nosso milênio.

Para realizar essa leitura crítica, tomamos por fundamento os Estudos do Imaginário na perspectiva interdisciplinar da hermenêutica simbólica. As teorias e autores que sustentam essa epistemologia permitem exercícios reflexivos sobre o caráter histórico e cultural do 
fenômeno artístico, tornando-se campo relevante para problematizar a experiência humana de maneira multidimensional. Nossa perspectiva antropológica analisa o imaginário a partir da tensão entre forças biográficas e sociais na linha teórica de Gilbert Durand.

Wunenburger (2007, p. 35) aponta que, independente do método com que se pretende operacionalizar, o imaginário pode ser "apreendido como uma esfera organizada de representações na qual fundo e forma, partes e todo se entrelaçam". Portador de uma dinâmica própria e de forte plasticidade, o imaginário, materializado sob a forma de literatura, comporta uma constituição linguística singular e revela, de alguma forma, aspectos da subjetividade de um autor. A matéria prima com que se desenha o imaginário de um autor são imagens abrigadas em seu eu profundo, que vão se retecendo às experiências vividas e assumindo formas reconhecíveis de um contexto sócio-histórico. Para o referido autor (2007, p. 40), "embora cada indivíduo imaginante esteja dotado de uma função de onirismo, de simbolização e de mitificação, nem todos atualizam o conjunto das práticas imaginantes". A capacidade de alcançar um nível estético ou simbólico novo é o que constitui, para ele, o mistério da criação artística.

0 texto organiza-se em diferentes camadas de sentido, constelando metáforas, símbolos, arquétipos, esquemas - matéria-prima do imaginário passível de significação, de sentido e de decifração. Esses elementos substanciais traduzem criativamente o imaginário de um autor e o imaginário social e cultural no qual se insere. Portanto, convirá lembrar o fato de que, na perspectiva que aqui assumimos, coloca-se sob suspeição a ideia de um autor transportando-se de imediato para dentro de sua obra para nela se manifestar de modo demiúrgico.

Conforme Saramago (apud ARNAUT, 2008, p. 88-89):

[...] de fingimentos de verdade e de verdade de fingimento se fazem[...] as histórias. Contudo, em minha opinião, e a despeito do que, no texto, se nos apresenta como uma evidência material, a história que ao leitor mais deveria interessar não é a que, liminarmente, lhe é proposta pela narrativa. Um livro não está formado somente por personagens, conflitos, situações, lances, peripécias, efeitos de estilo, exibições ginásticas de técnicas de narração - um livro é, acima de tudo, a expressão de uma parcela identificada da humanidade: o seu autor. Pergunto-me até, se o que determina o leitor a ler não será uma secreta esperança de descobrir no interior do livro - mais do que a história que lhe será narrada - a pessoa invisível mas omnipresente do seu autor. Tal como o entendo, o romance é uma máscara que esconde, e ao mesmo tempo, revela, os traços do romancista. Com isto, não pretendo sugerir ao leitor que se entregue durante a leitura a um trabalho de detective, ou antropólogo, procurando pistas ou removendo camadas geológicas, ao cabo das quais, como um culpado ou uma vítima, ou como um fóssil, se encontraria o autor... Muito pelo contrário: o autor está no livro todo, o autor é todo o livro, mesmo quando o livro não consiga ser todo o autor.

Nesse sentido, entendemos que o imaginário autoral manifesta-se por meio de uma enunciação turbulenta à medida em que o texto não se autoengendra. $\mathrm{O}$ autor ficará implicado através de uma consciência que se revela por uma situação enunciativa plural que ele orquestra formando na obra um complexo puzzle de vozes e discursos (BUESCU, 1998) ao qual o leitor terá acesso para com ele necessariamente jogar. 0 conteúdo marcado por uma vivacidade arquetipal abre-se a

Memorare, Tubarão, v. 8, n. 2, jul./dez. 2021. ISSN: 2358-0593 
atualizações, dada a função poética que lhe imprime um permanente dinamismo criador, motivo pelo qual o leitor, no contato com o texto, faz emergir múltiplas possibilidades interpretativas capazes de recriar imaginários.

\section{Imaginário e Literatura: um olhar sobre o projeto estético e político de Saramago em A Jangada de Pedra}

Com a apresentação de uma sequência de insólitos eventos associados à confluência da vida de personagens, numa ambientação não menos fantástica, inicia-se e desfia-se a narrativa de $A$ Jangada de Pedra, romance de José Saramago, escrito em 1986, traduzido em mais de vinte línguas, e que recebeu também uma adaptação fílmica, em 2002, por George Sluizer.

O enredo orbita um conflito inexplicável: a Península Ibérica está se separando do continente europeu e passa a se deslocar no Atlântico. Há grande mobilização da imprensa com manchetes nas redes de televisão, rádios e jornais, informando os inauditos fenômenos e as providências que deveriam ser tomadas para se encontrar os responsáveis.

Os protagonistas, imersos nesse contexto, vivenciam isoladamente fatos estranhos em seu cotidiano e, gradativamente, encontram-se e se unem em busca de explicações. É Joana Carda que se nos apresenta à primeira vista: ao riscar o chão (em solo português) com uma vara de negrilho, sente-se culpada pela separação da Península Ibérica do restante da Europa. Maria Guavaira, na Costa da Galiza, é quem desfia uma meia de lã azul que não termina de desfazer-se, formando um novelo imenso em forma de nuvem. Joaquim Sassa é personagem que se apresenta como capaz de uma tarefa sobre-humana, lançar uma pedra ao mar numa praia da cidade do Porto; a distância que esta percorre e o modo como o faz revela-se evento de impossível aceitação para o porte físico de Joaquim. José Anaiço, na parte inicial do romance, é seguido por uma revoada de estorninhos; sem aparente relação com a cisão da Europa, ele revela seu propósito somente no decorrer do enredo. Pedro Orce é muito sensível à contínua vibração vinda do solo, como se pudesse perceber as oscilações provocadas pelo movimento de Espanha e Portugal. 0 Cão Constante, que carrega um fio de lã azul à boca, juntase ao grupo. No início da trama, quando surge a fenda, é hesitante figura entre Espanha e França. Símbolo da fidelidade e guia do ser humano, a figura canina também sente as vibrações da terra. Não se pode desconsiderar a alusão que se faz à origem infernal do animal, dada pelo fato de este provir da região de Cerbère, fronteiriça à Espanha, onde supostamente passou e latiu Cérbero, guardião do Hades.

Enquanto o pedaço de continente (Jangada de pedra) vai se deslocando, as personagens principais empreendem uma viagem de descoberta da ilha e de seus fatos estranhos. A viagem é feita pelo grupo em uma galera, conduzida por Maria Guavaira e puxada inicialmente por um, posteriormente por dois cavalos. Na iminência de um acidente com a ilha dos Açores, o que evidencia o lugar para onde se desloca a jangada, a população se desespera. As duas mulheres do grupo decidem ter relações com Pedro Orce, o que provoca um clima de tensão nos viajantes, ainda que permaneçam juntos. A Jangada de Pedra para em 
uma posição em que Portugal fica voltado para os Estados Unidos e a Espanha para a Europa.

Embora as demais personagens não percebam o movimento da terra, Pedro Orce afirma que ela ainda treme, o que acaba por se confirmar com a retomada do movimento peninsular, de modo a girar, durante um mês, em torno de seu próprio eixo. Finalmente, o movimento cessa e as mulheres percebem que estão grávidas. Morre Pedro Orce no momento em que a galera para e se percebe que a terra não treme mais. 0 grupo descansa para depois retomar a viagem.

É notável como essa obra de Saramago potencializa um conjunto de imagens que se tecem no imaginário do leitor, o qual embrenha-se no jogo recriador para inferir sentidos.

A Jangada de pedra é título que se revela alegórico, amalgamando múltiplas significações. Como embarcação, remete ao tema da navegação e da viagem. Notadamente, é referência histórica, literária e mitológica tecendo caminhos de navegação dados por conexões possíveis em todo tecido hipertextual. A matéria de que é feita - a pedra - metaforiza a ação humana de construção. É fundação. Segundo Chevalier e Gheerbrant (1996), a pedra é símbolo da Terra-mãe. 0 espaço - a Jangada de Pedra - metaforiza a Península Ibérica que se desloca pelo Atlântico, em um tempo sem marcas cronológicas precisas, um tempo labiríntico condensado no espaço e na ação: a viagem percurso da humana vivência, tecida de paixões, de desejos, de experiências e de aprendizagens.

Desse modo, A Jangada de Pedra, com essa configuração alegórica, evoca, no imaginário do leitor, uma pluralidade de viagens, colocando em marcha o percurso dos heróis em busca de si mesmos. 0 texto nos transporta, pelas ondas do imaginário mítico, à Odisseia, à Arca de Noé e a outros lugares de memória cultural de onde podemos ponderar sobre a condição e a identidade do ser humano. Não nos escapa, inclusive, a remetência à figura de Dom Quixote, o cavaleiro andante, não belo e impulsionado por sua "loucura", entretanto, tenaz em sua busca fomentada pelo lema "fazer o bem" e encontrar sua nobre donzela imaginária.

As construções metafóricas da linguagem saramaguiana colocamnos, nesta obra, diante de expressivas imagens: a dos estorninhos a fazer estranhas revoadas sobre a cabeça de José Anaiço, que poderia evocar a busca de novos sentidos e novas direções; os tremores de terra sentidos por Pedro Orce, que poderiam remeter às necessárias mudanças a serem engendradas no solo da realidade da Península; a pedra, arremessada por Joaquim Sassa ao mar, ao pular infinitamente contra a gravidade, que pode metaforizar os incômodos da realidade instituída. 0 cão, fiel e vigilante, que percorre o labirinto infernal da Península o tempo todo ao lado dos companheiros, como psicopompo, mostra-se "guia do homem na noite da morte, após ter sido seu companheiro no dia da vida". (CHEVALIER; GHEERBRANT, 1996, p. 176). Sua figuração revela-se iniciatória, pois evoca a morte e o recomeçar da nova vida. Os fios de lã destecidos por Maria Guavaira podem evocar a desconstrução da história ibérica, o desfiar da cultura hegemônica e a busca de um novo tecido social e imaginário, de uma nova forma de conviver inaugurada com o encontro desses 
personagens-heróis do cotidiano que se fazem no comum da vida. Guavaira - de sonoridade próxima à Guarvaia, a primeira cantiga medieval cantada em solo lusitano - é a Ariadne que fornece os fios para construir essa nova trama da história.

Como matéria mítica, renova-se a imagem de Ulisses, herói paradigmático que, segundo a crença, fundou a cidade de Lisboa (BORGES, 1983, p. 39) e, na condição de líder, convida seus companheiros a uma notável aventura. Igualmente é possível reler a figura bíblica de Noé, importante personagem para o imaginário cristão, imagem literarizada para semantizar a construção de uma nova humanidade.

A vara com que Joana Carda risca o chão pode metaforizar a vara de condão com sua natureza mágica, ou o lápis a traçar fantasticamente a narrativa - axis mundi a revelar o poder de recriação da estória a partir do desígnio de refazer, pela palavra, a História. Vara mágica e de poder clarividente, sob mãos femininas - vale ressaltar essa evidência nas obras de Saramago - faz acordar para o sentimento e para a consciência transformadora.

Esse conjunto de imagens metafóricas e simbólicas, advindas de diversificados lugares do imaginário - tais como as narrativas da tradição na forma de contos e mitos; a literatura e a história -, apresenta-se semantizado em um novo discurso que se tece labiríntico no corpo vivo da palavra literária, engendrando faces de um comprometimento social, cultural, ético, político e estético do autor lusitano.

Essa constelação de imagens retecida pelo feérico, pelo mitológico e pelo alegórico convida a reflexões sobre temáticas convergentes, vale dizer, sobre a memória e as identidades, que expressam problemáticas de relevo na pós-modernidade, a serem lidas em muitos âmbitos, inclusive o do contexto histórico e político em que a escrita da obra se aclimata. Sabe-se que o contexto histórico de produção desse romance coincide com Portugal em face da tensão pós-Abril, que remete à integração de Portugal na Comunidade Econômica Europeia (como nação periférica) e identificação, ao lado da Espanha, com suas excolônias.

As situações dramáticas apresentadas na narrativa compõem-se como uma rede de imagens que se orientam para a ideia de uma ruptura, de um deslocamento sobre si mesmo e em direção ao outro, uma procura por outro lugar. Ao transformar a Jangada de pedra na principal personagem da narrativa evoca-se um posicionamento político possivelmente alusivo à resistência de Portugal às alianças com a Europa civilizada - referida ironicamente como "mãe amorosa" (SARAMAGO, 1988, p. 31). Ao girar sobre si mesma, a jangada é passível de conotar um movimento de autoconhecimento, assim como o deslocamento à deriva em direção ao Atlântico para finalmente estacionar entre África e América do Sul - continentes que sofreram sérias violências advindas do projeto colonizador - pode sugerir não apenas novas parcerias econômicas, políticas e culturais, mas a esperança de construção de uma comunidade com aqueles que compartilham a mesma língua - busca de identidade e de pertença a um entrelugar cultural. Vale assinalar o final da viagem, em que Joana 
Carda, Maria Guavaira e, depois, todas as mulheres engravidam - uma nova geração se tece.

A Ibéria transformada em jangada leva o leitor a acercar-se da gloriosa história do povo português em suas grandes navegações em busca de um novo mundo, entretanto com uma outra visão, marcada pelo olhar crítico de quem revê os acontecimentos e vislumbra novas perspectivas - fundamentais ao Iberismo, que se revela como utopia sociopolítica de Saramago. A motivação artística é a imaginação utópica como práxis poética e política necessária para realização da utopia libertária - uma espécie de "sonho diurno" 3 - a qual vislumbra o escritor português.

Na voz de Saramago:

Algumas vezes este romancista, preso nas malhas da ficção que ia tecendo, chegou a imaginar-se transportado na delirante jangada de pedra em que transformava a Península Ibérica, flutuando sobre o mar atlântico, a caminho do Sul e da Utopia. A peculiaridade da alegoria era transparente: embora prolongando algumas semelhanças com o mais comum dos emigrantes que parte para outras terras a buscar a vida, prevalecia, neste caso, uma definitiva e substancial diferença, a de viajarem também comigo, na migração inaudita, o meu próprio país [...] (ARNAUT, 2008, p. 77)

O motivo da viagem é, inegavelmente, o eixo simbólico estruturante da narrativa e assume duas feições: de um lado, a utópica - na projeção de uma identidade que vai se construindo pela autoconsciência e pelo sentimento de pertença coletiva; de outro, a paródica - na medida de um olhar ao revés do próprio projeto colonizador. Importante assinalar que nem sempre a paródia está atrelada a um propósito risível, aliás, essa "repetição com distância crítica, que marca a diferença em vez da semelhança" pode evocar a moderna autoreflexividade, como aponta Linda Hutcheon (1989, p. 13, 17).

Os mitos, relidos, projetados em transfiguração barroca", enraizados em novo contexto, são literalizados, podendo atuar por meio de inversões, de paródias, ou de aparências", conforme assinala Wunenburger (2007, p. 50-51). Nas palavras do autor:

trata-se então não de um retorno do mito, como se tratasse tão somente de adaptar um mito antigo às condições de sensibilidade ou de inteligibilidade atuais, mas de um retorno ao mito com uma intenção ficcional. 0 novo texto do mito é então obtido por procedimentos controlados de ajustes, de sobreposição, de miscigenação, de entrecruzamentos intertextuais[...], que com frequência não são destituídos, por seu turno, de humor, de ironia ou de sentido paródico.

Ao tecer a obra com a presença do imaginário mítico, fazendo reverberar vozes ancestrais, Saramago traça seu estilo de escrita, que, a todo tempo, sobrepõe o dito que se destina a ser ouvido. Reitera o autor: "Quero com isto significar que é como narrador oral que me vejo quando escrevo e que as palavras são por mim escritas tanto para serem lidas como para serem ouvidas. Ora, o narrador oral não precisa de

\footnotetext{
${ }^{3}$ Conforme Benjamin Abdala Junior, inspirado em Ernst Bloch: sonho diurno "é o sonho de quem procura novos horizontes [...] Essa atitude é mais adequada do que o sonho noturno, que teima obsessivamente em olhar para trás, melancolicamente contemplando as ruínas". (ABDALA JR., Benjamin. De vôos e ilhas: literaturas e comunitarismos. São Paulo, Ateliê Editorial, 2003. p. 18).
} 
pontuação, fala como se estivesse a compor música [...] (SARAMAGO apud ARNAUT, 2008, p. 87)

No compasso das transformações paradigmáticas de nosso século, a narrativa de Saramago se faz como uma forma escritural contemporânea, desestruturando modelos de narrativas anteriormente reverenciadas. Faz-se como processo de desarticulação de toda pretensão ao universal, de todo ritual para demarcação de poderes e glórias. Com diversos planos discursivos e fora de qualquer plano monopolizador do tempo, do espaço e da imaginação, faz reverberar elaborações ampliadas que abrigam a complexidade. Essa dissolução na forma de narrar incorpora um conjunto de vozes. Neste conjunto polifônico, faz reverberar o imaginário mítico, o imaginário erudito da literatura, o imaginário do povo também por meio de provérbios ou ditos populares - procedimento estilístico que se revela no uso do discurso indireto livre, traduzindo o fluxo do pensamento, na elaboração de uma linguagem revolta, composta de parágrafos longos, sem pontuação a não ser vírgulas e alguns pontos em uma configuração também ela labiríntica e hipertextual.

Nesse sentido, o texto de Saramago projeta um imaginário marcado por uma gramática poética de complexa textura e aguda inventividade, que associa o motivo da viagem com o do labirinto. A descontinuidade da narrativa - em razão de intromissões do narrador, da ausência de indicação dos interlocutores, da pontuação, entre outras marcas de estilo - aliada a um sistema denso de imagens portadoras de forma e força criativa -, estabelecem um pacto ficcional que desafia o leitor com uma demanda semelhante à de Teseu.

Em obras hipertextuais, como essa, fica sob a tutela do leitor a cocriação em face de um labirinto de possibilidades. Para Rosenstiehl (1988, p. 252-3), há traços definidores do labirinto: o convite à exploração e a capacidade de voltar a pontos percorridos para obter alguma segurança; a exploração sem um mapa previamente elaborado, uma vez que não se tem a visão global; a exigência de uma inteligência astuciosa para que se prossiga e progrida sem cair em armadilhas, permanecendo em constantes circunvoluções.

Saramago, de alguma forma, nesta obra, convida-nos a adentrar uma arquitetura imaginária que nos faculta uma aventura de navegação. À semelhança das produções artísticas de Escher, que tendem a representar construções impossíveis, com explorações do infinito e metamorfoses, o leitor é arremessado no interior de um processo de exploração labiríntico. Os traços e colunas textuais dessa edificação conduzem seu explorador para além das malhas da obra impressa. 0 inusitado uso da pontuação potencializa o complexo itinerário imaginário, tecido de múltiplas rotas que ativam a capacidade mnemônica para construção de sentidos, motivam o leitor a recuperar o passado, a questionar o presente e a buscar projeções de futuro. Nessa viagem imóvel e imaginária possibilitada pela arte literária, o leitor refaz caminhos de descobertas e significação, reescrevendo a história. Carece a ele, no transitar por entre as tramas dos signos verbais e não verbais, encontrar o fio de Ariadne (ou não); importa, ao fim e ao cabo, a travessia lúdica, reflexiva e crítica desse labirinto que ficcionalmente está traçado com o lápis da obscura realidade. 
Como peça desse labirinto, encontra-se o insólito, já de início anunciado, propondo um jogo ficcional que se abre para uma aventura imaginária capaz de subverter a lógica cartesiana. No contexto da obra, forças complexas anunciam-se para engendrar e surpreender o leitor, lançando-o a administrar incertezas, assim como as que, efetivamente, compõem a trajetória humana. Há mais coisas desconhecidas do que podemos pensar. Subjaz a ideia de uma causalidade diferente das que conhecemos para as quais o autor torna o leitor um aliado.

Convirá acrescentar o fato de que a intromissão do fantástico na narrativa saramaguiana cria, também, intencionalmente, rupturas com o modo realista como as crônicas de viagem tomavam corpo - gênero com o qual também as obras fazem diálogo, uma vez que foram permanentemente usadas nas comunicações coloniais. 0 tensionamento entre os elementos de realidade e de invenção vai aos poucos traduzindo a experiência do autor e sendo compartilhada com o leitor na busca indelével de novas referências que demandam uma necessária reinvenção do olhar. Trata-se de um recurso engenhoso que dá força ao projeto estético do escritor revelando-se um potente sinal de sua consciência de linguagem. Importa lembrar que, na concepção de Roas (2014, p. 8), a presença do fantástico, como um modo de expressão, um propósito estético, torna-se "um discurso em constante relação com esse outro discurso, que é a realidade entendida sempre como construção social". A fricção entre essas duas instâncias leva o leitor a experimentar profunda inquietação, uma vez que lhe falta a coerência dos sentidos. Essa inquietação desestabiliza relações sólidas e pouco questionadas e introduz novas possibilidades de realização.

As incursões pelo fantástico, como pinceladas a compor cada quadro literário construído pelo autor com refinada sensibilidade, em contraponto a pretensos cenários realistas, como os noticiários, manchetes nas redes de televisão e rádios - cujas ações eram também alvo de fervorosas críticas do autor - marcam o texto de uma causalidade mágica e criam efeitos de ruptura, de maneira a provocar inquietação.

Em síntese, esta obra sob nossa mira, ao configurar-se como urdidura de elementos imaginários, de códigos diversos e de diferentes linguagens, reunindo, em palimpsesto, textos culturais, épocas civilizatórias, sonhos e ideais humanos apresenta-se como a escrita de uma viagem que se tece no interior de um labirinto sígnico. Seus temas tramam-se pela perpetuação de diferentes imaginários, modulando a compreensão de cada época. Os grandes navegadores, Noé, Ulisses, heróis históricos, míticos e literários inscrevem no corpo do texto o factual, o sagrado e o insólito, revelando múltiplas possibilidades para o impulso da aventura humana em busca do conhecimento.

A narrativa convida a esse deslocamento do leitor, arremessando-o para dentro de seu labirinto interior, de modo que a escrita se torna pretexto para a busca de si e da expressão de si - uma espécie de odisseia interna. Conforme Hatoum (1994, p. 77)

A identidade não deve ser uma adesão passiva ao real com que fomos enformados. Forma compacta, o estereótipo é uma fábrica de convenções, um antídoto contra a invenção. Nesse sentido, a identidade é uma busca. 
Para um escritor, essa busca se perde em um labirinto de vivências e experiências, mediado pelo aparato da linguagem. [...]

A escrita da viagem é, portanto, metáfora para o encontro: do autor com o leitor. Atualiza o sujeito no seu permanente movimento de formação e de reformulações na busca de um lugar cultural. A escrita da viagem é navegação, como gesto humanizador por excelência, escrita enigmática da vida e para a vida nos seus trânsitos e desígnios. Memória e porvir que fazem renovar o homem no seu percurso iniciatório pelos labirintos das formas.

A língua portuguesa é a possibilidade de expressão e de compartilhamento desse gesto transfigurador e decifrador de novas paisagens. Nessa cartografia imaginária, o texto literário revela-se pátria líquida, jangada que se move à deriva da imaginação, barco-ventre que navega na extensão infinita dos possíveis e projeta, na fluidez das águas, o olhar ilimitado para novas navegações. Eis a dimensão metapoética e mitopoética da arte da escrita de Saramago.

\section{Considerações finais}

Afirma Saramago, em 1989, no Jornal de Letras, Artes e Ideias: "Esse romance [A Jangada de pedra] em que afasto a Península Ibérica da Europa, não precisaria dizê-lo, é o efeito último de um ressentimento histórico. Provavelmente só um português poderia ter escrito este livro" (ARNAUT, 2008, p. 80). É com essa compreensão que o escritor português engendra, em singular estética ficcional, as severas críticas no âmbito da política, da sociedade e das formas abusivas de autoridade. Se o século XVI lusitano se vangloria do maior empreendimento de sua história com as Grandes Navegações, o século XXI/XXI anuncia um ponto de inflexão: Portugal revisita sua conquista ultramarina e questiona sua própria identidade, em um movimento de autoconsciência, que, a todo tempo, destece a memória e retece a história.

Esse parece ser o tema que move o imaginário saramaguiano na composição da obra A Jangada de pedra. 0 romance, ao reatualizar o motivo da viagem, em tensas tramas que sobrepõem o real e o simbólico, tecidos por fios da memória e da história, carrega-nos para os caminhos densos de um labirinto, em que o jogo demanda provas, a navegação acessa uma inteligência arguta para mapear sentidos nos caminhos que se bifurcam.

Como um entrelugar imaginário em que conflui o lúdico e o lúcido, aberto ao percurso-navegação, o hipertexto-labirinto se oferece ao leitor como desafio capaz de projetar, em novas paragens, relações do homem com o mundo e com outro. Esse efeito de deslocamento propiciado pelo jogo artístico da linguagem - imagens ação - sugerem, a partir da obra analisada, a re-escritura de uma nova épica tecida pela ruptura e alimentada pelo desejo de um novo modo de estar vivo e de poder conviver.

Esse movimento que se refaz no próprio corpo do texto, entrevê no plano do conteúdo, a viagem como recorrência simbólica, remetendo ao conhecimento na exploração do mundo e do texto, no enfrentamento dos limites do próprio viajante-leitor, na trajetória da jangada ao encontro com o "outro" e consigo mesmo, constituindo-se como um 
modo de encenação do diálogo entre identidades - o eu e o outro; autorleitor - movimento do olhar para construir novos pontos de vista. Assim, como substância imaginária, a viagem não figura apenas deslocamento individual no espaço geográfico ou no tempo, mas mostra-se também como deslocamento social e cultural (MACHADO; PAGEAUX, 1997). Formam-se novos sujeitos, apresentam-se novos caminhos, constroem-se outras alianças.

Em seu criativo projeto estético e político, revela profunda consciência de linguagem, incitando reflexões sobre a importância dos laços de afeto em resistência às severas forças do discurso hegemônico eis por que o trabalho com o imaginário ganha força. Como forma cifrada de manifestação humana, ato simbólico, por excelência, de expressão do imaginário, a literatura revela-se lugar de memória de onde se enseja ponderar sobre a condição humana e seus possíveis.

0 motivo da viagem traduz-se como aventura de uma humana aprendizagem a realizar-se tanto no corpo inextrincável do texto, quanto nos fluxos labirínticos da existência.

\section{Referências}

ABDALA JR., Benjamin. De vôos e ilhas: literaturas e comunitarismos. São Paulo: Ateliê Editorial, 2003.

ARAUJO, Alberto F.; BAPTISTA, Fernando P. Variações sobre o imaginário: domínios, teorizações, práticas hermenêuticas. Lisboa: Instituto Piaget, 2003.

ARNAUT, Ana Paula. José Saramago. Lisboa: Edições 70, 2008.

BORGES, J. L. Sete noites. São Paulo: Max Limonad, 1983.

BUESCU, Helena. Em busca do autor perdido: histórias, concepções, teorias. Lisboa: Cosmos, 1998.

CASSIRER, Ernst. Ensaio sobre o homem. São Paulo: Martins Fontes, 1994.

CHEVALIER, Jean; GHEERBRANT, Allain. Dicionário de símbolos: mitos, sonhos, costumes, gestos, formas, figuras, cores, números. Trad. Vera da Costa e Silva et al. 10. ed. Rio de Janeiro: José Olympio,1996.

DURAND, Gilbert. As estruturas antropológicas do imaginário. Trad. Hélder Godinho. São Paulo: Martins Fontes, 1997.

A Imaginação simbólica. Lisboa: Edições 70, 1993.

. Campos do Imaginário. Lisboa: Instituto Piaget, 2000.

HATOUM, M. Literatura e identidade nacional. In: Remate de males. Campinas, v.14,1984.

HUTCHEON, Linda. Uma teoria da paródia. Ensinamento das formas de arte do século XX. Lisboa: Edições 70, 1989.

MACHADO, Álvaro Manuel; PAGEAUX, Daniel-Henry. Literatura portuguesa, literatura comparada e Teoria Literária. Lisboa: Edições 70, 1981.

MAFFESOLI, Michel. Notas sobre a pós-modernidade: o lugar faz o elo. Rio de Janeiro: Atlântica, 2004. 
MORIN, E. O paradigma Perdido. Portugal: Europa-America, 1999.

Os sete saberes necessários à educação do futuro. 8. ed. São Paulo: Cortez; Brasília, DF: UNESCO, 2003.

ROSENSTIEHL, P. Labirinto. Enciclopédia Einaudi. Lisboa: Imprensa nacional, v.13,1988.

ROAS, David. A ameaça do fantástico. São Paulo: Unesp, 2014.

SARAMAGO, J. A jangada de pedra. São Paulo: Companhia das Letras, 1988.

WUNENBURGER, Jean-Jacques. O Imaginário. São Paulo: Edições Loyola, 2007.

Artigo enviado em: 03/10/2021. Aprovado em: 25/11/2021. 